\title{
General Base Swap Preserves Activity and Expands Substrate Tolerance in Hedgehog Autoprocessing
}

Jing Zhao", Daniel A. Ciulla Jian Xie, Andrew G. Wagner, Drew A. Castillo, Allison S. Zwarycz, Zhongqian Lin, Seth Beadle, José-Luis Giner, Zhong Li , Hongmin Li, Nilesh Banavali, Brian P. Callahan*, and Chunyu Wang*

(Supporting Information) 
A

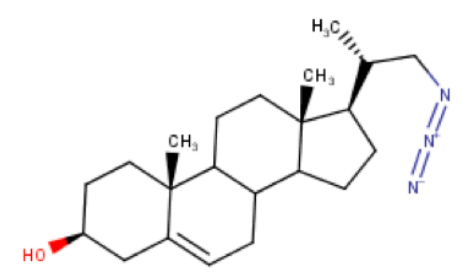

B

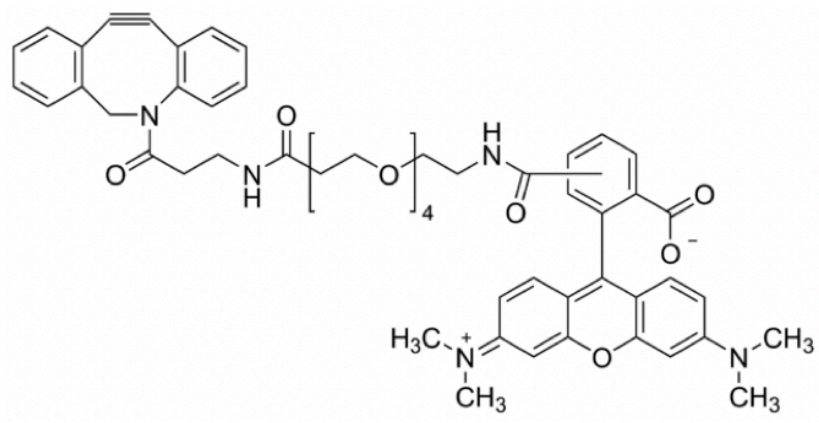

Fig. S1. Structures of (A) 22-azido sterol and (B) dibenzocyclooctyne-PEG4-Fluor 545 (SigmaAldrich, 760773) for copper-free click chemistry used in cholesterylation UV-gel.

\section{WT C1A D46H}
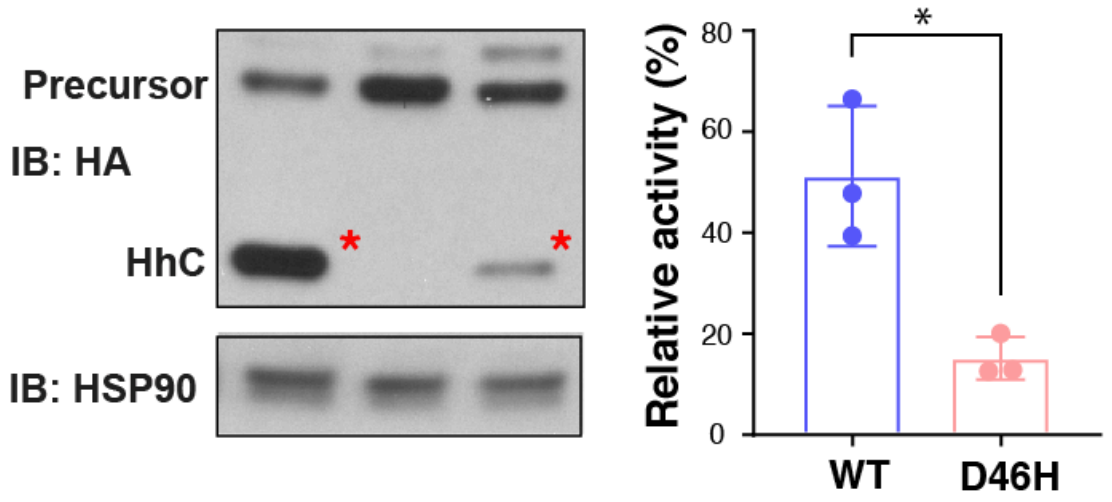

Fig. S2. Sonic Hh D46H mutant maintains autoprocessing activity in human 293T cells by Western blot. WT and C1A mutant were used as positive and negative control for intracellular Hh autoprocessing activity, respectively. Relative activity was calculated by the ratio of $\mathrm{HhC}$ and HhC+Precursor. * $(\mathrm{p}<0.05, \mathrm{n}=3)$. WT Sonic Hh can undergo efficient autoprocessing, resulting in a clear HhC band and diminished amount Hh precursor in Western blot. As expected, the C1A mutation completely blocks precursor turnover, with no detectable HhC. The D46H mutant, although less efficient than the WT, can still mediate autoprocessing, in general accord with the FRET experiments. The lower efficiency of D46H in human cell culture is not completely understood, but may be due to the more complex cellular or endoplasmic reticulum (ER) environment where Hh autoprocessing occurs. 
A

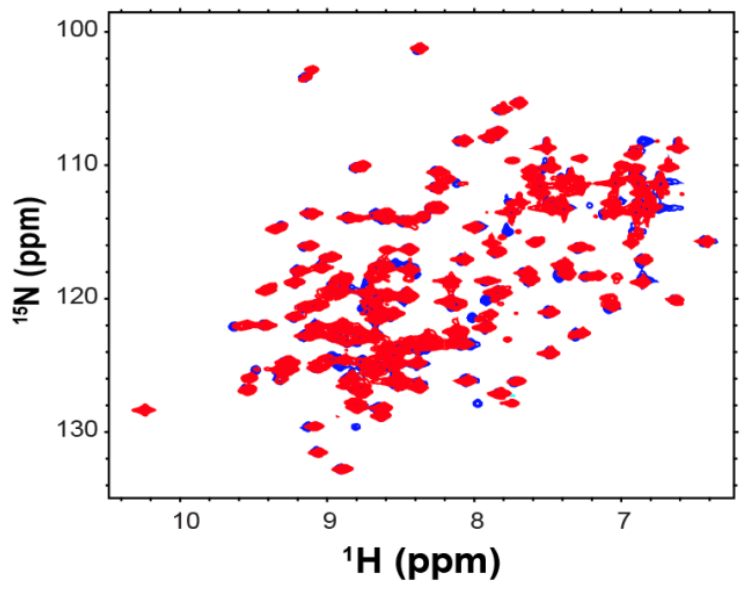

B

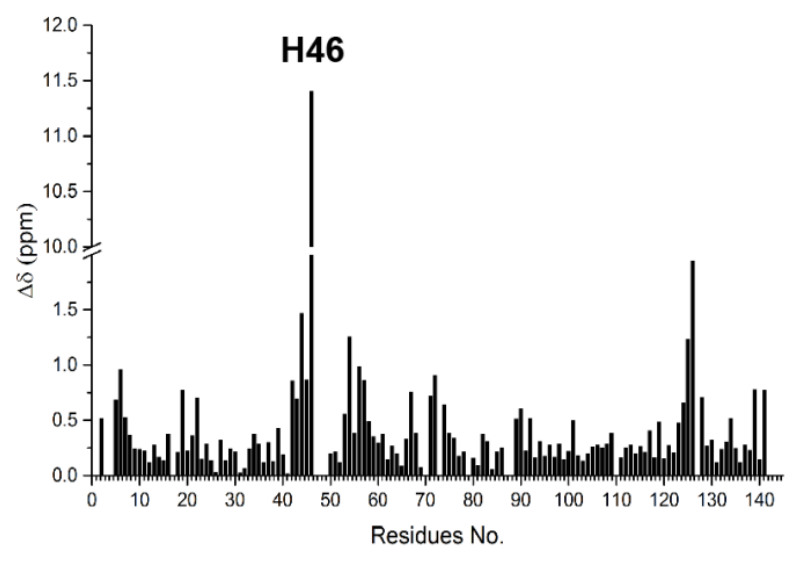

Fig. S3. Chemical shift perturbation (CSPs) of D46H relative to WT. (A) ${ }^{1} \mathrm{H}_{-}{ }^{15} \mathrm{~N}$ HSQC spectrum overlay of D46H (in red) and WT (in blue). (B) CSPs against residue number of D46H, showing minimal CSP except for the site of mutation residue $\mathrm{H} 46$ and residues close to it in space, e.g. residues near residue 125 .
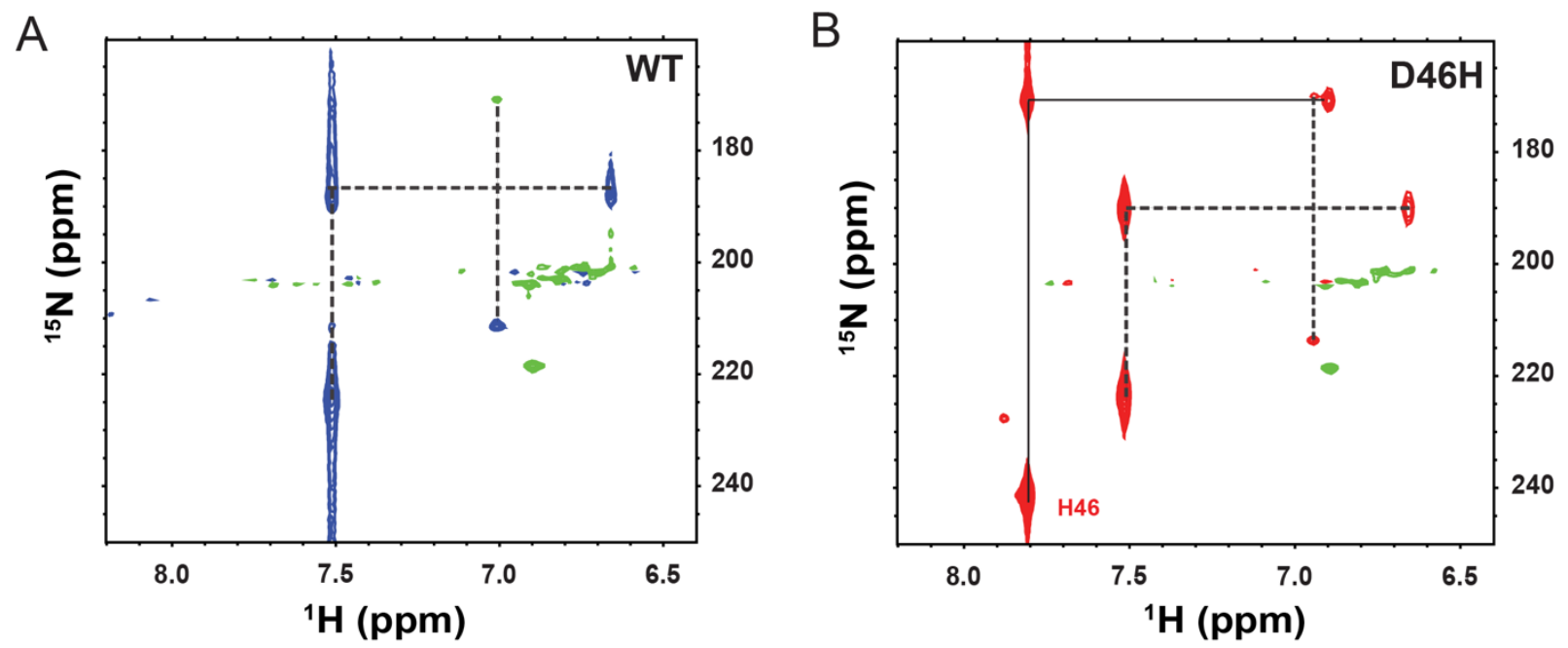

Fig. S4. Assignment of $\mathrm{H} 46$ in long-range ${ }^{1} \mathrm{H}-{ }^{15} \mathrm{~N}$ HMQC spectrum. (A) Long-range ${ }^{1} \mathrm{H}-{ }^{15} \mathrm{~N}$ HMQC spectrum of WT Hint at $\mathrm{pH}$ 7.2. (B) Long-range ${ }^{1} \mathrm{H}-{ }^{15} \mathrm{~N}$ HMQC spectrum of the $\mathrm{D} 46 \mathrm{H}$ Hint at $\mathrm{pH}$ 7.2. Peaks connected by dotted lines were shared by D46H and WT. Peaks connected by solid line were assigned to $\mathrm{H} 46$. 

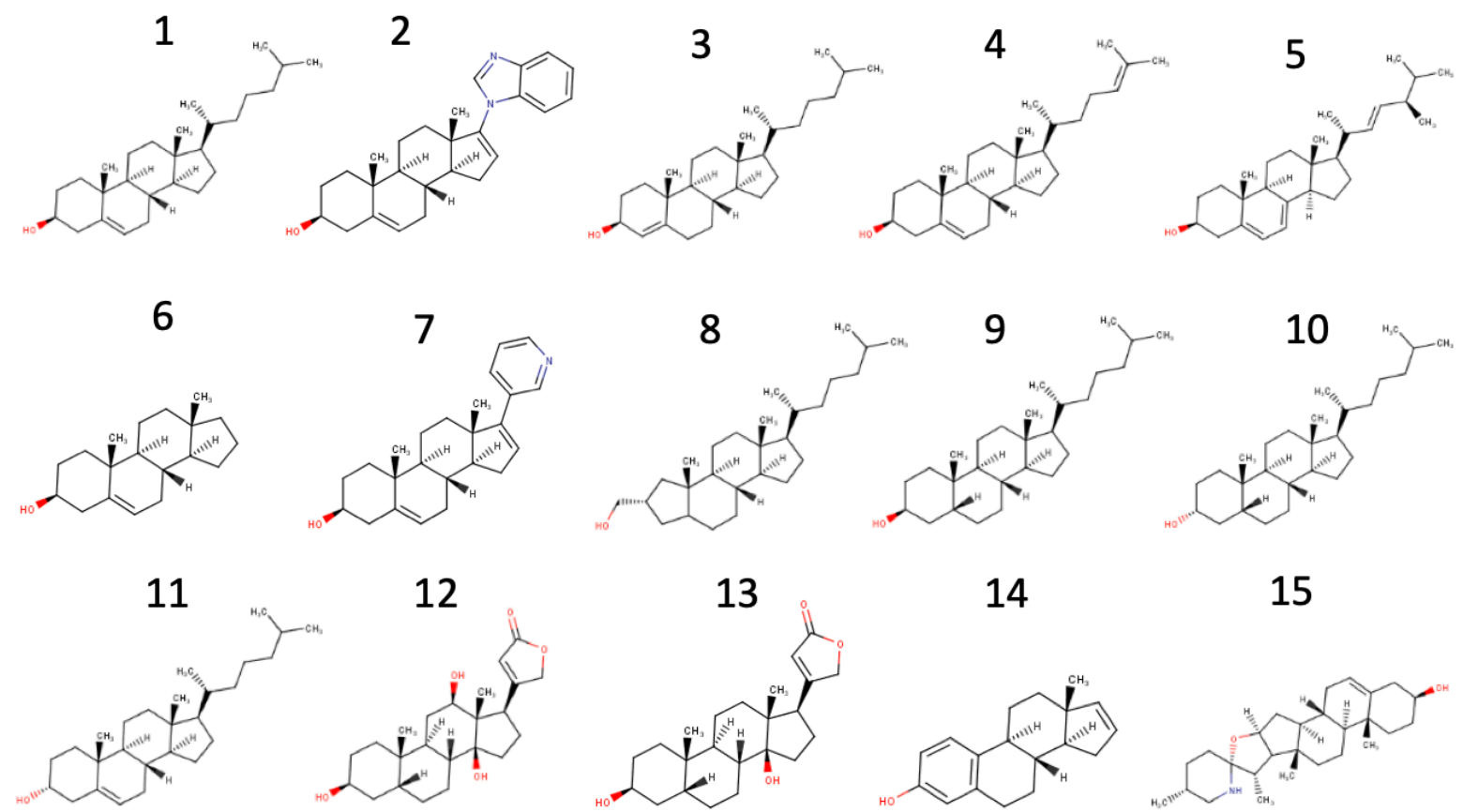

14

15
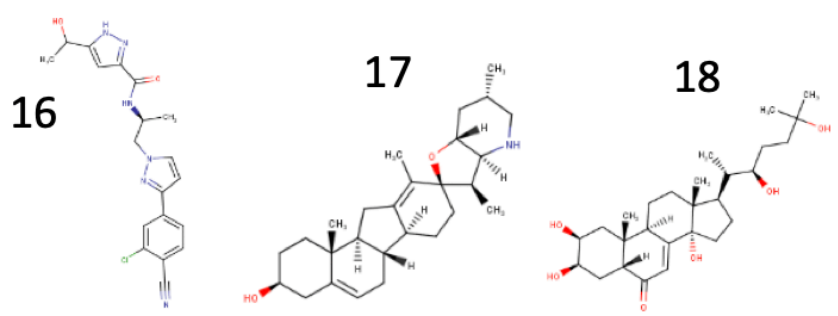

Fig. S5. Chemical structure of 18 different compounds used in the substrate screening. 


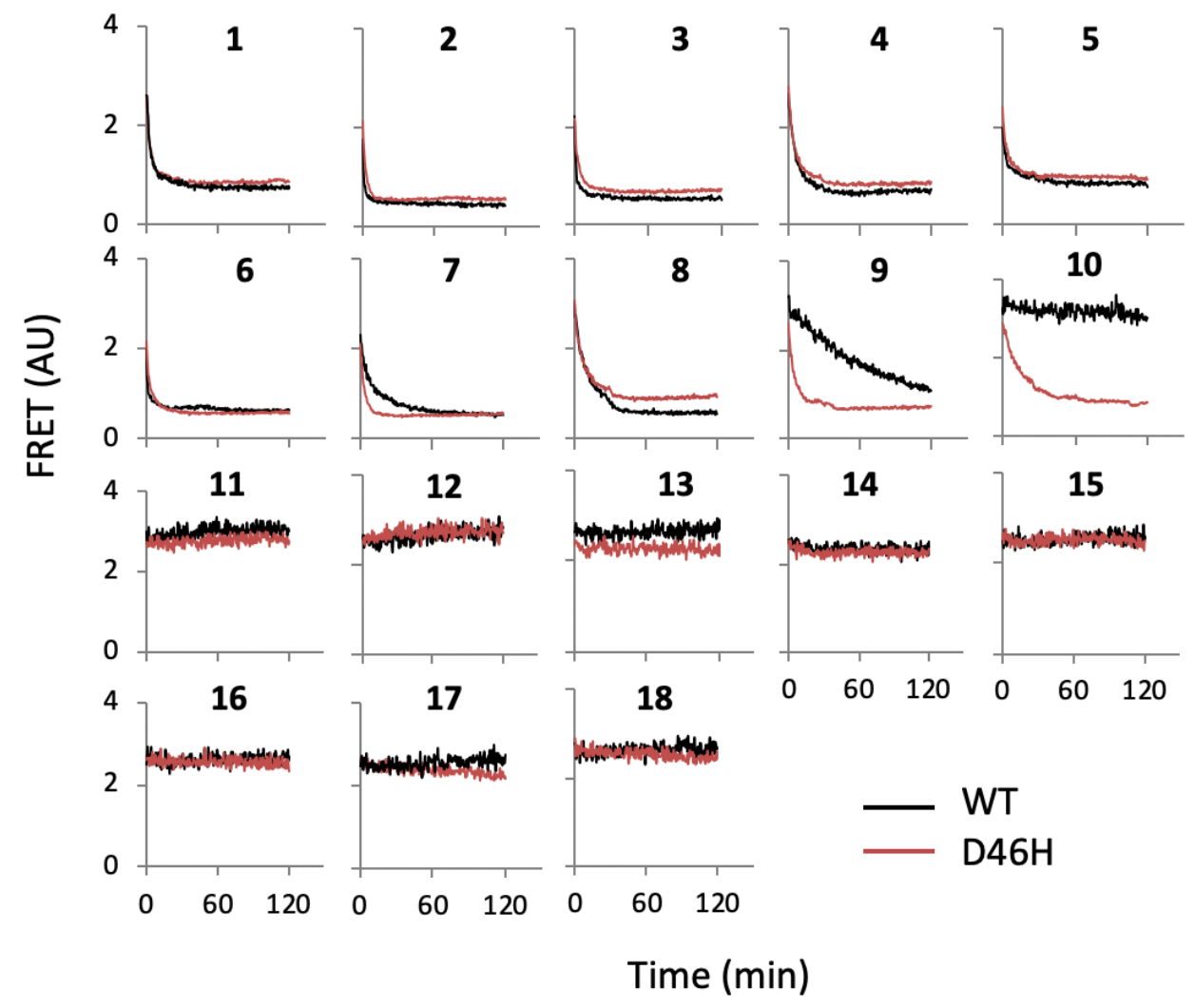

Fig. S6. Substrate activity screen of WT (black) and D46H (red) toward 18 different compounds by FRET assay. Compounds 11 to 18 are not utilized by both WT and D46H. 

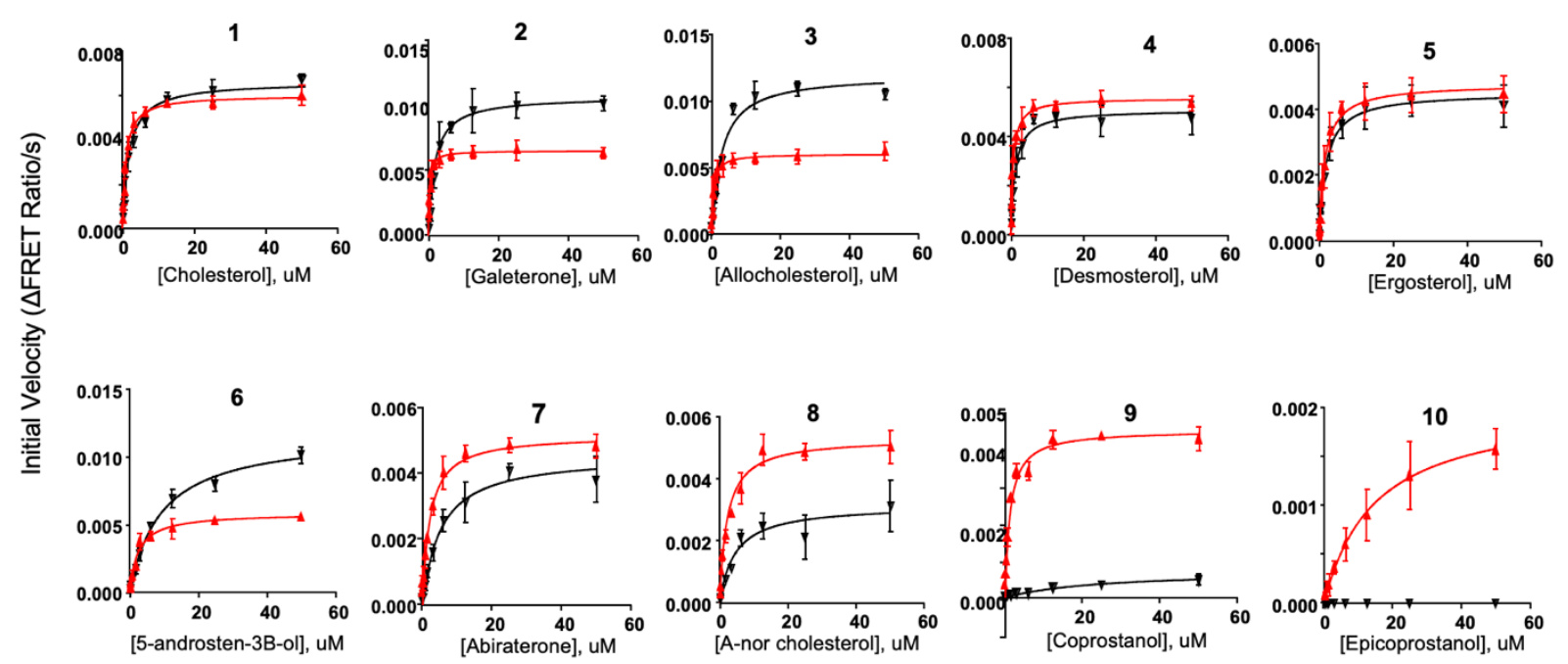

Fig. S7. Michaelis-Menten enzyme kinetics of WT and D46H toward 10 active substrates (compounds 1 to 10). Black - WT, Red - D46H.
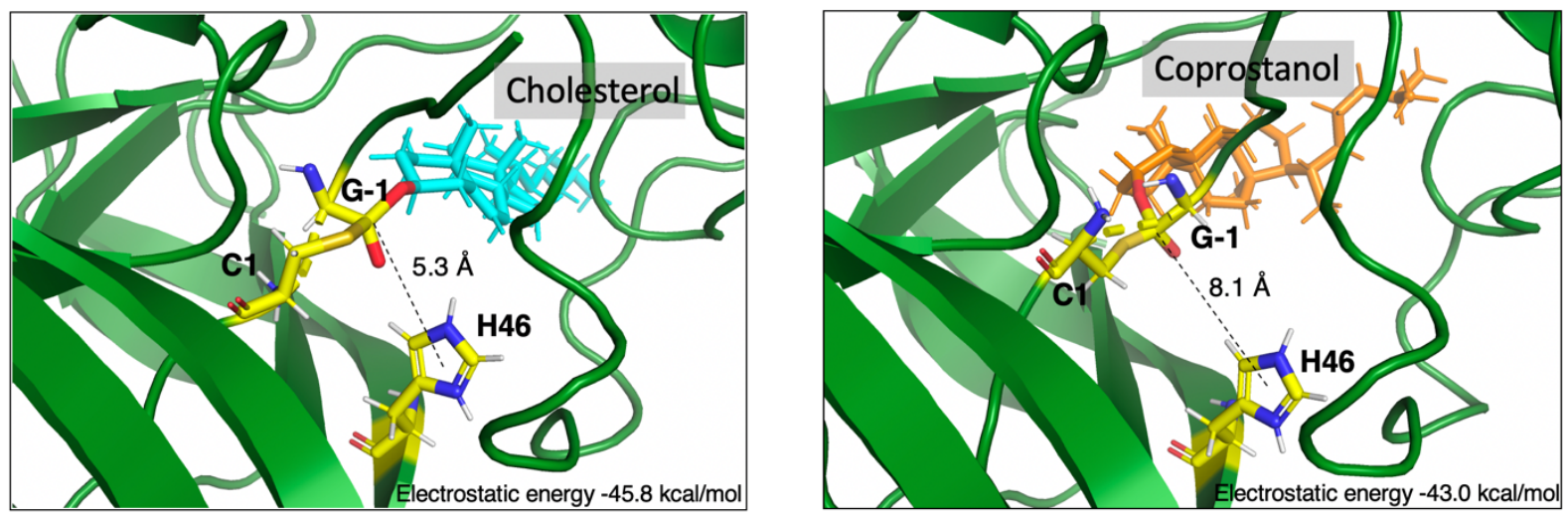

Fig. S8. The model of cholesterol (left) and coprostanol (right) tetrahedral intermediates (negatively charged) interacting with H46 sidechain (positively charged) through electrostatic interactions. The distance is measured between the center-of-mass of H46 sidechain atoms and the center-of-mass of the three electronegative atoms in the tetrahedral transition state (sterol oxygen, G-1 carbonyl oxygen, and $\mathrm{C} 1$ sidechain sulfur). Coulombic electrostatic interaction energies were computed between all sidechain atoms of $\mathrm{H} 46$ and the three electronegative atoms of the tetrahedral transition state using the CHARMM program. 
Table S1. Catalytic kinetics in substrate activity screening

\begin{tabular}{|c|c|c|c|c|c|c|}
\hline \multirow[t]{2}{*}{ Substrate } & \multicolumn{3}{|c|}{ WT } & \multicolumn{3}{|c|}{ D46H } \\
\hline & $\begin{array}{c}k_{\max } \\
\left(\mathbf{x} 10^{-3} \mathbf{s}^{-1}\right)\end{array}$ & $\begin{array}{c}K_{M} \\
\left(\mathbf{x 1 0 ^ { - 6 }} \mathrm{M}\right)\end{array}$ & $\begin{array}{c}k_{\max } / K_{M} \\
\left(\mathbf{x} 10^{3} \mathbf{M}^{-1} \mathbf{s}^{-1}\right)\end{array}$ & $\begin{array}{c}k_{\max } \\
\left(\mathbf{x} 10^{-3} \mathrm{~s}^{-1}\right)\end{array}$ & $\begin{array}{c}K_{M} \\
\left(\times 10^{-6} \mathrm{M}\right)\end{array}$ & $\begin{array}{c}k_{\max } / K_{M} \\
\left(\mathbf{x} 10^{3} \mathbf{M}^{-1} \mathbf{s}^{-1}\right)\end{array}$ \\
\hline 1. Cholesterol & 3.8 & 1.9 & $2.1 \pm 6 \%$ & 3.6 & 1.0 & $3.7 \pm 12 \%$ \\
\hline 2. Galeterone & 13 & 1.9 & $8.0 \pm 16 \%$ & 5.6 & 0.3 & $19 \pm 11 \%$ \\
\hline 3. Allocholesterol & 6.5 & 2.9 & $2.3 \pm 9 \%$ & 4.0 & 0.6 & $7.6 \pm 11 \%$ \\
\hline 4. Desmosterol & 2.2 & 1.2 & $1.9 \pm 9 \%$ & 3.5 & 0.7 & $5.7 \pm 13 \%$ \\
\hline 5. Ergosterol & 2.9 & 1.9 & $1.6 \pm 15 \%$ & 3.6 & 1.6 & $2.3 \pm 11 \%$ \\
\hline 6. 5 -androsten- $3 \beta$-ol & 8.7 & 9.4 & $0.94 \pm 8 \%$ & 3.9 & 2.5 & $1.6 \pm 7 \%$ \\
\hline 7. Abiraterone & 2.1 & 5.8 & $0.38 \pm 20 \%$ & 4.2 & 2.1 & $2.0 \pm 3 \%$ \\
\hline 8. A-nor Cholestanol & 1.1 & 3.6 & $0.29 \pm 18 \%$ & 2.5 & 2.2 & $1.3 \pm 15 \%$ \\
\hline 9. Coprostanol & 0.3 & 25 & $0.011 \pm 8 \%$ & 2.9 & 1.2 & $2.4 \pm 7 \%$ \\
\hline 10. Epicoprostanol & $<0.01$ & $>50$ & $<0.2$ & 1.0 & 16 & $0.063 \pm 16 \%$ \\
\hline 11. Epicholesterol & - & - & $<0.2$ & - & - & $<0.2$ \\
\hline 12. Digoxigenin & - & - & $<0.2$ & - & - & $<0.2$ \\
\hline 13. Digitoxigenin & - & - & $<0.2$ & - & - & $<0.2$ \\
\hline 14. 16-Estratetraenol & - & - & $<0.2$ & - & - & $<0.2$ \\
\hline 15. Solasodine & - & - & $<0.2$ & - & - & $<0.2$ \\
\hline 16. Darolutamide & - & - & $<0.2$ & - & - & $<0.2$ \\
\hline 17. Cyclopamine & - & - & $<0.2$ & - & - & $<0.2$ \\
\hline 18. Ecdysone & - & - & $<0.2$ & - & - & $<0.2$ \\
\hline
\end{tabular}

All assays were carried out at $30^{\circ} \mathrm{C}$. 
Table S2. Data collection and refinement statistics.

\begin{tabular}{|c|c|}
\hline Wavelength & 1.12709 \\
\hline Resolution range & $22.63-1.36(1.409-1.36)$ \\
\hline Space group & P 61 \\
\hline Unit cell & 78.38178 .38137 .3519090120 \\
\hline Total reflections & $131976(9616)$ \\
\hline Unique reflections & $28204(2753)$ \\
\hline Multiplicity & $4.7(3.5)$ \\
\hline Completeness (\%) & $99.50(97.19)$ \\
\hline Mean I/sigma(I) & $16.55(1.04)$ \\
\hline Wilson B-factor & 15.47 \\
\hline R-merge & $0.0582(0.9033)$ \\
\hline R-meas & $0.06552(1.068)$ \\
\hline R-pim & $0.02956(0.5559)$ \\
\hline $\mathrm{CC} 1 / 2$ & $0.999(0.653)$ \\
\hline $\mathrm{CC}^{*}$ & $1(0.889)$ \\
\hline Reflections used in refinement & $28170(2730)$ \\
\hline Reflections used for R-free & $1994(194)$ \\
\hline R-work & $0.1706(0.4110)$ \\
\hline R-free & $0.1949(0.4463)$ \\
\hline CC(work) & $0.975(0.708)$ \\
\hline $\mathrm{CC}($ free $)$ & $0.983(0.753)$ \\
\hline Number of non-hydrogen atoms & 1309 \\
\hline macromolecules & 1148 \\
\hline solvent & 161 \\
\hline Protein residues & 146 \\
\hline RMS(bonds) & 0.006 \\
\hline RMS(angles) & 1.26 \\
\hline Ramachandran favored $(\%)$ & 97.90 \\
\hline Ramachandran allowed (\%) & 2.10 \\
\hline Ramachandran outliers (\%) & 0.00 \\
\hline Rotamer outliers (\%) & 1.56 \\
\hline Clashscore & 4.33 \\
\hline Average B-factor & 19.59 \\
\hline macromolecules & 17.96 \\
\hline solvent & 31.26 \\
\hline
\end{tabular}

Statistics for the highest-resolution shell are shown in parentheses. 


\section{Experimental procedures}

FRET-based cleavage assay. For the FRET assays, autoprocessing of D46H and WT were monitored at $30{ }^{\circ} \mathrm{C}$ by the loss of FRET ratio using a BioTek $\mathrm{H} 1$ plate reader, as previously described ${ }^{1}$. The FRET ratio refers to the emission at $540 \mathrm{~nm}$ divided by the emission at $460 \mathrm{~nm}$ following excitation at $400 \mathrm{~nm}$. Samples $(100 \mu \mathrm{L}$ in total) containing FRET-active construct CHhC-Y $(100 \mathrm{nM})$ in BIS-TRIS propane buffer (100 mM, pH 7.1) with EDTA (5 mM), NaCl (100 $\mathrm{mM})$, TCEP (5 mM), and Fos-Choline-12 $(1.5 \mathrm{mM})$ were transferred to a 96 well plate. To initiate cholesterylation reactions, cholesterol was added from an ethanol stock to $100 \mu \mathrm{M}$ with final ethanol concentration $4 \%(\mathrm{v} / \mathrm{v})$.

Synthesis of clickable sterol. A mixture of (20S)-21-iodo-6 $\beta$-methoxy-20-methyl-3 $\alpha, 5 \alpha$ cyclopregnane $(360 \mathrm{mg})$ and sodium azide $(500 \mathrm{mg})$ was stirred in a 2:1 mixture of DMSO and tetrahydrofuran (THF,12 mL). After the reaction was complete $(4 \mathrm{~h})$, the reaction mixture was partitioned between water and ether, the organic layer dried with $\mathrm{Na}_{2} \mathrm{SO}_{4}$, and the solvent removed under reduced pressure. A sample of the product was deprotected by treatment with $2 \%$ trifluoroacetic acid (TFA) in dichloromethane (DCM) for $5 \mathrm{mins}$, evaporation of the solvents with a stream of $\mathrm{N}_{2}$, and cleavage of the trifluoroacetate ester with $20 \%$ triethylamine (TEA) in $\mathrm{MeOH}$ $\left(7 \mathrm{~h}, 40^{\circ} \mathrm{C}\right)$. After evaporation of the solvents with a stream of $\mathrm{N}_{2}$, the desired product was obtained ((20S)-21-azidopregn-5-en-3 $\beta$-ol). ${ }^{1} \mathrm{H}$ NMR (600 MHz): 5.36-5.34 $(1 \mathrm{H}, \mathrm{m}), 3.56-3.49(1 \mathrm{H}, \mathrm{m})$, $3.371(1 \mathrm{H}, \mathrm{dd}, J=3.2,11.9 \mathrm{~Hz}), 3.051(1 \mathrm{H}, \mathrm{dd}, J=7.4,11.9 \mathrm{~Hz}), 1.056(3 \mathrm{H}, \mathrm{d}, J=6.6 \mathrm{~Hz}), 1.012$ $(3 \mathrm{H}, \mathrm{s}), 0.698(3 \mathrm{H}, \mathrm{s}) ;{ }^{13} \mathrm{C} \mathrm{NMR}(151 \mathrm{MHz}): 140.79,121.56,71.77,58.06,56.50 .53 .21,50.04$, $42.51,42.29,39.55,37.25,36.92,36.49,31.91,31.84,31.66,27.89$, 24.32, 21.04, 19,38, 17,79, 11.92 .

Gel-based cholesterylation assay. FRET constructs $\mathrm{C}-\mathrm{HhC} \mathrm{CWT}_{\mathrm{W}} \mathrm{Y}$ and $\mathrm{C}-\mathrm{HhC}_{\mathrm{D} 46 \mathrm{H}}-\mathrm{Y}$ were reacted with azide modified cholesterol for 3 hours at room temperature in the following solution containing: protein C-HhC-Y $(1 \mu \mathrm{M})$, BIS-TRIS propane buffer $(100 \mathrm{mM}, \mathrm{pH} 7.1)$ with EDTA $(5$ $\mathrm{mM}), \mathrm{NaCl}(100 \mathrm{mM}), \mathrm{DTT}(1 \mathrm{mM})$, and Fos-Choline-12 (1.5 mM). Each protein master-mix was divided into two $50 \mu \mathrm{L}$ fractions, one for ethanol $(4 \% \mathrm{v} / \mathrm{v}$, used for dissolving sterol) control and the other for cholesterol-azide $(100 \mu \mathrm{M})$ as substrate. After the 3-hour sterylation reaction, the protein was denatured by urea $(6 \mathrm{M})$ and cysteine thiols were blocked by addition of iodoacetamide (10 mM). Next, dibenzocyclooctyne-PEG4-Fluor 545 (Sigma Aldrich) was added to a final concentration of $30 \mu \mathrm{M}$ and reactions were left in the dark for $45 \mathrm{~min}$ at room temperature. Samples were stained by $5 \mathrm{x}$ bromophenol blue dye: SDS (10\%), DTT (500 mM), glycerol (50\%), Tris- $\mathrm{HCl}(500 \mathrm{mM}, \mathrm{pH} 6.8)$, and bromophenol blue dye $(0.05 \%)$ and boiled for 2 minutes on a $95^{\circ} \mathrm{C}$ heat block. Reactions were then resolved over $12 \%$ SDS-PAGE gel, imaged by UV light using a Bio-Rad Gel-Doc system, and finally stained by Coomassie Brilliant Blue.

Cell-based autoprocessing assay. Human 293T cells were grown in DMEM supplemented with $10 \%$ fetal bovine serum, streptomycin and penicillin. To generate stable cells, constructs encoding full-length WT and D46H human Sonic Hh (SHh), C-terminally tagged with a hemagglutinin (HA) epitope (FLAG-SHh-HA) were cloned into the retroviral vector pMSCVpuro. The retroviruses were produced in $293 \mathrm{~T}$ cells and used to infect $293 \mathrm{~T}$ cells. After 2 
days of infection, the stable cells were selected after puromycin treatment at $1 \mu \mathrm{g} / \mathrm{mL}$ for 4 days. To measure the processing abilities of the WT and $\mathrm{D} 46 \mathrm{H}$, the cell lysates were mixed with SDSPAGE sample buffer with $5 \%$ (v/v) $\beta$-mercaptoethanol, and separated by SDS-PAGE followed by HA immunoblotting. HSP90 was used as a loading control.

Protein Purification and NMR Sample Preparation. WT Drosophila melanogaster Hh Hint domain and $\mathrm{D} 46 \mathrm{H}$ were expressed in the E. coli strain BL21(DE3). Cells were grown at $37^{\circ} \mathrm{C}$ and induced with $0.5 \mathrm{mM} \mathrm{IPTG}$ at an $\mathrm{OD}_{600}$ of 0.5 , then grown for another $20 \mathrm{~h}$ at $16^{\circ} \mathrm{C}$. Cell pellets were lysed by sonication ( $3 \mathrm{sec}$ on and $6 \mathrm{sec}$ off for $6 \mathrm{~min}$ in total). Cell lysate was purified on a Ni-NTA (GE Healthcare) affinity column. N-terminal cleavage was induced by $0.2 \mathrm{M}$ hydroxylamine (HA) at $16{ }^{\circ} \mathrm{C}$ for $24 \mathrm{hrs}$. After cleavage, pure protein was collected in the flowthrough after loading on another Ni-NTA affinity column. Isotopic labeling was accomplished by growing cultures in M9 medium containing either $1 \mathrm{~g} / \mathrm{L}{ }^{15} \mathrm{NH}_{4} \mathrm{Cl}$ for a uniformly ${ }^{15} \mathrm{~N}$-labeled sample, or $1 \mathrm{~g} / \mathrm{L}^{15} \mathrm{NH}_{4} \mathrm{Cl}$ and $4 \mathrm{~g} / \mathrm{L}{ }^{13} \mathrm{C}$ Glucose (Cambridge Isotope Laboratories) for a uniformly ${ }^{15} \mathrm{~N},{ }^{13} \mathrm{C}$-labeled sample. The pure protein was concentrated and exchanged into NMR buffer, which was $1 \times$ PBS $\left(137 \mathrm{mM} \mathrm{NaCl}, 2.7 \mathrm{mM} \mathrm{KCl}, 10.1 \mathrm{mM} \mathrm{Na}_{2} \mathrm{HPO}_{4}, 1.76 \mathrm{mM} \mathrm{NaH}_{2} \mathrm{PO}_{4}\right)$ with $10 \mathrm{mM}$ DTT in $\mathrm{H}_{2} \mathrm{O} / \mathrm{D}_{2} \mathrm{O}(90 / 10)$ or $99.9 \% \mathrm{D}_{2} \mathrm{O}$ at $\mathrm{pH}$ 7.2. The final protein concentration of the NMR samples is $0.5 \mathrm{mM}$.

$\boldsymbol{p H}$ titration and $\boldsymbol{p} \boldsymbol{K}_{\boldsymbol{a}}$ calculation. Long range ${ }^{1} \mathrm{H}-{ }^{15} \mathrm{~N}$ HMQC spectra ${ }^{2}$ were optimized on a 600 $\mathrm{MHz}$ spectrometer for observing 2 or 3 bond ${ }^{1} \mathrm{H}-{ }^{15} \mathrm{~N}$ correlation in the sidechain of histidine. 3072 $\left(\mathrm{t}_{2}\right) \times 256\left(\mathrm{t}_{1}\right)$ complex data points with 96 scans were used. $205.0 \mathrm{ppm}$ was chosen as the center of the spectrum in ${ }^{15} \mathrm{~N}$ dimension with a spectral width of $90 \mathrm{ppm}$. The spectrum center in ${ }^{1} \mathrm{H}$ dimension was set as $4.7 \mathrm{ppm}$ for ${ }^{1} \mathrm{H}$ for better water suppression. A series of long range ${ }^{1} \mathrm{H}-{ }^{15} \mathrm{~N}$ HMQC spectra were recorded on $\mathrm{D} 46 \mathrm{H}$ at different $\mathrm{pH}$, including 3.55, 4.03, 4.45, 4.96, 5.41, 5.95, $6.55,7.23,7.55$ and 7.93, without notable precipitation of the protein. The $\mathrm{pH}$ values were measured by an Orion Star ${ }^{\mathrm{TM}} \mathrm{A} 111 \mathrm{pH}$ Benchtop Meter equipped with a $\mathrm{pH}$ micro electrode (Fisher Scientific, Fair Lawn, NJ), calibrated with pH 4.0, 7.0, and 10.0 standard solutions (Fisher Scientific, Fair Lawn, NJ). The pH of the samples was adjusted using 0.1 or $0.01 \mathrm{M} \mathrm{HCl} / \mathrm{NaOH}$. The observed ${ }^{15} \mathrm{~N}$ chemical shifts of the histidine imidazole ring $\left(N_{\delta}\right)$ were plotted against $\mathrm{pH}$ and fitted by a modified Henderson-Hasselbalch equation ${ }^{3,4}: \delta_{o b s}=\left(\left(\delta_{H A}+\delta_{A-} * 10^{n(p H-p K a)}\right) /\left(1+10^{n(p H-}\right.\right.$ $\left.{ }^{p K a)}\right)$, where $\delta_{o b s}, \delta_{H A}$, and $\delta_{A}$ - are the chemical shifts for the observed, protonated, and deprotonated species, respectively, and $\mathrm{n}$ is the Hill parameter to account for nonideality.

Crystal Structure of D46H Hh Hint domain. The purified D46H Hh Hint domain was concentrated to $12 \mathrm{mg} / \mathrm{ml}$ in a $1 \mathrm{x}$ PBS buffer supplemented with $10 \mathrm{mM}$ DTT. Initial crystallization conditions were established by screening the Hampton Research crystallization screen I, II, and index HT, using the hanging-drop vapor diffusion method. Upon optimization, large crystals were grown at room temperature in hanging drops, by mixing $1 \mu \mathrm{L}$ of $\mathrm{D} 46 \mathrm{H}$ and $1 \mu \mathrm{L}$ of reservoir solution containing 0.1 M HEPES, $\mathrm{pH} 7.5,3.4 \mathrm{M}$ sodium formate. The crystals of $\mathrm{D} 46 \mathrm{H}$ belong to space group $P 6_{1}$, with unit cell parameters of $a=78.381 \AA, b=78.381 \AA, c=37.351 \AA, \alpha=\beta=90^{\circ}$, $\beta=120^{\circ}$. Prior to data collection, all crystals were transferred to a cryo-protectant solution containing crystallization buffer with $20 \%$ glycerol. The crystals were flash-cooled directly in liquid nitrogen. Diffraction data for the D46H crystals were collected at $100 \mathrm{~K}$ at the beamline 141 of the Stanford Synchrotron Radiation Lightsource (SSRL). Data were processed, scaled, and reduced using the programs HKL2000 ${ }^{5}$ and Phenix suite ${ }^{6}$. 
The structure of the $\mathrm{D} 46 \mathrm{H}$ was determined using molecular replacement (MR) method with the WT Hh Hint domain (PDB: 1AT0) as a search model. The MR search and structure refinement were carried out using the Phenix program suite ${ }^{6}$, and iterative graphic modeling with the program Coot $^{7}$ (Table S2).

Substrate screening of cholesterol analogs. The substrate activity screen was performed over a series of FRET assays. These compounds have been chosen to investigate naturally occurring products and to probe changes in sterol A-ring selectivity. Cholesterol and solasodine are purchased from Sigma-Aldrich (St. Louis, MO, USA). Allocholesterol, desmosterol, ergosterol, 5-androsten-3B-ol, coprostanol, epicoprostanol, epicholesterol and 16-estratetraenol are obtained from Steraloids (Newport, RI, USA). Galeterone, abiraterone, darolutamide, cyclopamine, and ecdysone are purchased from Adooq Bioscience (Irvine, CA, USA). Digoxigenin and digitoxigenin are from MedChemExpress (Monmouth Junction, NJ, USA). A-nor cholestanol was prepared as previously described ${ }^{8}$. FRET decay was monitored and calculated as detailed earlier. In a black 96-well plate reaction samples were prepared as follows (100 $\mu \mathrm{L}$ total solution per well): FRET-active construct C-WT-Y or C-D46H-Y (100 nM), BIS-TRIS propane buffer (100 mM, pH 7.1), EDTA (5 mM), TCEP (5 mM), Fos-choline-12 (1.5 mM). In a secondary 96-well plate substrate stock solutions were prepared $(1.25 \mathrm{mM})$ in ethanol. Using a multi-channel pipettor, substrates were added to reaction wells to a final concentration of $50 \mu \mathrm{M},(4 \% \mathrm{v} / \mathrm{v}$ ethanol) and the reactions were followed over the course of 2 hours at $30^{\circ} \mathrm{C}$. For Michaelis-Menten experiments, sterol stock was serially diluted in a secondary 96-well plate, and then transferred to reaction wells using a multi-channel pipet. Final sterol concentrations ranged from $0.1 \mu \mathrm{M}$ to $50 \mu \mathrm{M}$. Kinetic parameters, $K_{M}$ and $k_{\max }$ were calculated separately. $K_{M}$ was derived from Michaelis-Menten graphs of initial rate of FRET loss $\left(V_{\mathrm{o}}\right)$ plotted as a function of increasing sterol concentration, using the equation $V_{O} / V_{\max }=[S] /\left([S]+K_{M}\right)^{9}$, where $V_{\max }$ represents the maximum rate, [S] is the substrate concentration and $K_{M}$ is the Michaelis constant representing substrate concentration at which the reaction rate is half of $V_{\max }$. Values for the first order rate of sterolysis, $k_{\max }$, were determined by fitting the full kinetic trace from reactions at the highest concentration of sterol to the equation $F R E T=A \times e^{(-k \max \times t)}+C$, where $t$ is time, and $C$ is the FRET signal at $t=\infty$ while $A+C$ is the initial FRET signal $(t=0)$.

NMR assignment of D46H and chemical shift perturbations (CSPs). All NMR experiments were recorded at $25{ }^{\circ} \mathrm{C}$ on a Bruker $800 \mathrm{MHz}$ spectrometer, equipped with a cryogenic probe. All Spectra were processed with topspin 3.5pl7 (Bruker) and NMRPipe/NMRDraw (John Marino Group, NIST) ${ }^{10}$ and analyzed using Sparky 3.115 (Goddard and Kneller, UCSF) ${ }^{11}$. The assignment of WT Hh Hint domain was published previously ${ }^{12}$, with BMRB (http://www.bmrb.wisc.edu) ID number 19156. The assignment of D46H was based on a series of 3D spectra using a uniformly ${ }^{15} \mathrm{~N},{ }^{13} \mathrm{C}$-labeled sample, including $\mathrm{HNCACB}, \mathrm{CBCACONH}, \mathrm{HNCA}$, $\mathrm{HNCO}$ and $\mathrm{HNCACO} .{ }^{1} \mathrm{H}-{ }^{15} \mathrm{~N}$ HSQC experiments were recorded with 8 scans, a recycle delay of $1.0 \mathrm{~s}, 2048\left(\mathrm{t}_{2}\right) \times 400\left(\mathrm{t}_{1}\right)$ complex data points and spectral width of $16 \mathrm{ppm}$ in the ${ }^{1} \mathrm{H}$ dimension and $40 \mathrm{ppm}$ in the ${ }^{15} \mathrm{~N}$ dimension. HNCA, HNCACB and CBCACONH were recorded with 8 scans, $2048\left(\mathrm{t}_{3}\right) \times 80\left(\mathrm{t}_{1}\right) \times 128\left(\mathrm{t}_{2}\right)$ data points, and spectral width of $13 \mathrm{ppm}$ in the ${ }^{1} \mathrm{H}$ dimension, $40 \mathrm{ppm}$ in the ${ }^{15} \mathrm{~N}$ dimension and $70 \mathrm{ppm}$ in the ${ }^{13} \mathrm{C}$ dimension. HNCO and HNCACO were recorded with 8 scans and 32 scans, respectively, $2048\left(\mathrm{t}_{3}\right) \times 64\left(\mathrm{t}_{1}\right) \times 160\left(\mathrm{t}_{2}\right)$ data points, and spectral width of $15 \mathrm{ppm}$ in the ${ }^{1} \mathrm{H}$ dimension, $40 \mathrm{ppm}$ in the ${ }^{15} \mathrm{~N}$ dimension and $25 \mathrm{ppm}$ in the ${ }^{13} \mathrm{C}$ dimension. 
Linear prediction ${ }^{13}$ and zero-filling ${ }^{14}$ were used to obtain complex data matrixes before Fourier transformation to improve resolution. CSPs of D46H relative to WT were calculated by equation ${ }^{15}: \Delta_{\delta}=\left(100^{*} \Delta_{\mathrm{H}}{ }^{2}+\Delta_{\mathrm{N}}{ }^{2}\right)^{0.5}$, where $\Delta_{H}$ and $\Delta_{N}$ are the differences between the ${ }^{1} \mathrm{H}$ and ${ }^{15} \mathrm{~N}$ chemical shifts in ${ }^{1} \mathrm{H}_{-}{ }^{15} \mathrm{~N}$ HSQC spectrum of the D46H and WT protein.

Molecular modeling of the tetrahedral transesterification transition state. A Drosophila melanogaster (Dme) WT precursor model reported in a previous study ${ }^{8}$ was used as a template to model the tetrahedral transesterification transition state structure for $\mathrm{D} 46 \mathrm{H}$ constructs. This structure has five terminal residues of the $\mathrm{N}$-terminal hedgehog ligand domain and cholesterol bound to a hypothetical sterol-recognition-region (SRR) domain structure in an orientation conducive to reactivity. A 3D model for coprostanol downloaded from the Zinc database ${ }^{16}$ was manually put in a similar orientation as cholesterol using Chimera ${ }^{17}$. A homology model was generated for $\mathrm{D} 46 \mathrm{H}$ using the MODELLER software ${ }^{18}$ with the best model chosen using the DOPE ${ }^{19}$ and GA341 ${ }^{20}$ energy functions. Two models were thus generated of $\mathrm{D} 46 \mathrm{H}$ with either cholesterol or coprostanol bound. All further modeling was done using the program CHARMM, version $\mathrm{c} 43 \mathrm{~b} 2^{21,22}$ with the CHARMM36 force field for protein ${ }^{23}$ and cholesterol ${ }^{24}$, and CGENFF parameters for coprostanol ${ }^{25,26}$. Initial inputs were generated using the CHARMM-GUI PDBREADER module ${ }^{27}$ and a Restrained Geometries and Topology Switching (RGATS) strategy ${ }^{28}$ was used to model discrete steps of the autoprocessing reaction. For each bond breaking or formation modeled through topology switching, all protein non-hydrogen atoms were harmonically restrained with a force constant of $10 \mathrm{kcal} / \mathrm{mol} / \AA$ and the model was minimized using 5000 steps of Steepest Descent (SD) minimization and 5000 steps of Adopted Basis NewtonRaphson (ABNR) minimization with an energy change tolerance of $0.001 \mathrm{kcal} / \mathrm{mol}$. The restraint was then removed and the same minimization was repeated. For each transesterification transition state structure, additional restraints were applied to get bonding distances between the carbonyl carbon and both the cysteine sidechain sulfur atom and the sterol oxygen atom to yield a tetrahedral structure in the models. H46 were modeled in its protonated states. Coulombic electrostatic interaction energies were computed between all sidechain atoms of H46 and the three electronegative atoms of the tetrahedral transition state (Cys sulfur, carbonyl oxygen, and sterol oxygen) using the CHARMM program. 


\section{References}

(1) Owen, T. S.; Ngoje, G.; Lageman, T. J.; Bordeau, B. M.; Belfort, M.; Callahan, B. P. Förster Resonance Energy Transfer-Based Cholesterolysis Assay Identifies a Novel Hedgehog Inhibitor. Anal. Biochem. 2015, 488, 1-5. https://doi.org/10.1016/j.ab.2015.06.021.

(2) Glc, I. I. I. Tautomeric States of the Active-Site Histidines of Phosphorylated and Unphosphorylated I11 Glc, a Signal-Transducing Protein from Escherichia Coli, Using Two-Dimensional Heteronuclear NMR Techniques J.G. Protein Sci. 1993, 2, 543-558. Du, Z.; Shemella, P. T.; Liu, Y.; McCallum, S. A.; Pereira, B.; Nayak, S. K.; Belfort, G.; Belfort, M.; Wang, C. Highly Conserved Histidine Plays a Dual Catalytic Role in Protein Splicing: A PKa Shift Mechanism. J Am. Chem. Soc.2009, 131 (32), 11581-11589. https://doi.org/10.1021/ja904318w.

(4) Webb, H.; Tynan-Connolly, B. M.; Lee, G. M.; Farrell, D.; O’Meara, F.; Søndergaard, C. R.; Teilum, K.; Hewage, C.; McIntosh, L. P.; Nielsen, J. E. Remeasuring HEWL PKa Values by NMR Spectroscopy: Methods, Analysis, Accuracy, and Implications for Theoretical PKa Calculations. Proteins Struct. Funct. Bioinforma. 2011, 79 (3), 685-702. https://doi.org/10.1002/prot.22886.

(5) Otwinowski, Z.; Minor, W. Processing of X-Ray Diffraction Data Collected in Oscillation Mode. Methods Enzymol. 1997, 276, 307-326. https://doi.org/10.1016/S00766879(97)76066-X.

(6) Adams, P. D.; Afonine, P. V.; Bunkóczi, G.; Chen, V. B.; Davis, I. W.; Echols, N.; Headd, J. J.; Hung, L. W.; Kapral, G. J.; Grosse-Kunstleve, R. W.; McCoy, A. J.; Moriarty, N. W.; Oeffner, R.; Read, R.J.; Richardson, D. C.; Richardson, J. S.; Terwilliger, T. C.; Zwart, P. H. PHENIX: A Comprehensive Python-Based System for Macromolecular Structure Solution. Acta Crystallogr. Sect. D Biol. Crystallogr. 2010, 66 (2), 213-221. https://doi.org/10.1107/S0907444909052925.

(7) Emsley, P.; Lohkamp, B.; Scott, W. G.; Cowtan, K. Features and Development of Coot. Acta Crystallogr. Sect. D Biol. Crystallogr. 2010, 66 (4), 486-501. https://doi.org/10.1107/S0907444910007493.

(8) Ciulla, D. A.; Wagner, A. G.; Liu, X.; Cooper, C. L.; Jorgensen, M. T.; Wang, C.; Goyal, P.; Banavali, N. K.; Pezzullo, J. L.; Giner, J. L.; Callahan, B. P. Sterol A-Ring Plasticity in Hedgehog Protein Cholesterolysis Supports a Primitive Substrate Selectivity Mechanism. Chem. Commun. 2019, 55 (12), 1829-1832. https://doi.org/10.1039/c8cc09729a.

(9) Goudar, C. T.; Sonnad, J. R.; Duggleby, R. G. Parameter Estimation Using a Direct Solution of the Integrated Michaelis-Menten Equation. Biochim. Biophys. Acta - Protein Struct. Mol. Enzymol. 1999, 1429 (2), 377-383. https://doi.org/10.1016/S01674838(98)00247-7.

(10) Delaglio, F.; Grzesiek, S.; Vuister, G. W.; Zhu, G.; Pfeifer, J.; Bax, A. NMRPipe: A Multidimensional Spectral Processing System Based on UNIX Pipes. J. Biomol. NMR 1995, 6 (3), 277-293. https://doi.org/10.1007/BF00197809.

(11) Goddard, Td.; Kneller, D. G. Sparky 3. Univ. California, San Fr. 2004, 14, 15.

(12) Xie, J.; Du, Z.; Callahan, B.; Belfort, M.; Wang, C. 1H,13C, And15N NMR Assignments of a Drosophila Hedgehog Autoprocessing Domain. Biomol. NMR Assign. 2014, 8 (2), 279-281. https://doi.org/10.1007/s12104-013-9500-8.

(13) Zhu, G.; Bax, A. Improved Linear Prediction of Damped NMR Signals Using Modified "Forward-Backward" Linear Prediction. J. Magn. Reson. 1992, 100 (1), 202-207 
(14) Ernst, Richard, R.; Bodenhausen, G.; Wokaun, A. Principles of Nuclear Magnetic Resonance in One and Two Dimensions Vol. 14. Magn. Reson. Imaging 1987, 6 (3), 349. https://doi.org/10.1016/0730-725X(88)90413-4.

(15) Zhao, J.; Huvent, I.; Lippens, G.; Eliezer, D.; Zhang, A.; Li, Q.; Tessier, P.; Linhardt, R. J.; Zhang, F.; Wang, C. Glycan Determinants of Heparin-Tau Interaction. Biophys. J. 2017, 112 (5), 921-932. https://doi.org/10.1016/j.bpj.2017.01.024.

(16) Irwin, J. J.; Shoichet, B. K. ZINC - A Free Database of Commercially Available Compounds for Virtual Screening. J. Chem. Inf. Model. 2005, 45 (1), 177-182. https://doi.org/10.1021/ci049714+.

(17) Pettersen, E. F.; Goddard, T. D.; Huang, C. C.; Couch, G. S.; Greenblatt, D. M.; Meng, E. C.; Ferrin, T. E. UCSF Chimera - A Visualization System for Exploratory Research and Analysis. J. Comput. Chem. 2004, 25 (13), 1605-1612. https://doi.org/10.1002/jcc.20084.

(18) Sali, A; Blundell, T. L. Comparative Protein Modelling by Satisfaction of Spatial Restraints. J. Mol. Biol. 1993, 243, 779-815.

(19) Shen, M.-Y.; Sali, A. Statistical Potential for Assessment and Prediction of Protein Structures. Protein Sci. 2006, 15, 2507-2524. https://doi.org/10.1110/ps.062416606.Instead.

(20) Melo, F.; Sanchez, R.; Sali, A. Statistical Potentials for Fold Assessment. Protein Sci. 2002, 11, 430-448. https://doi.org/10.1017/CBO9781107415324.004.

(21) Brooks, B. R.; Bruccoleri, R. E.; Olafson, B. D.; States, D. J.; Swaminathan, S.; Karplus, M. CHARMM: A Program for Macromolecular Energy, Minimization and Dynamics Calculations. J. Compu 1983, 4 (2), 187-217.

(22) Brooks, B. R.; Brooks, C. L.; Mackerell, A. D.; Nilsson, L.; Petrella, R. J.; Roux, B.; Won, Y.; Archontis, G.; Bartels, C.; Boresch, S.; Caflish, A.; Caves L.; Cui, Q.; Dinner, A.R.; Feig, M.; Fischer, S.; Gao, J.; Hodoscek, M.; Im, W.; Kuczera, K.; Lazaridis, T.; Ma, J.; Qvchinnikov, V.; Paci, E.; Pastor, R. W.; Post, C.B.; Pu, J. Z.; Schaefer, M.; Tidor, B.; Venable, R. M.; Woodcock, H.L.; Wu, X.; Yang, W.; York, D. M.; Karplus, M. CHARMM: The Biomolecular Simulation Program. J. Comput. Chem. 2009, 30 (10), 1545-1614. https://doi.org/10.1002/jcc.21287.

(23) Best, R. B.; Zhu, X.; Shim, J.; Lopes, P. E. M.; Mittal, J.; Feig, M.; MacKerell, A. D. Optimization of the Additive CHARMM All-Atom Protein Force Field Targeting Improved Sampling of the Backbone $\varphi, \psi$ and Side-Chain X1 and X2 Dihedral Angles. $J$. Chem. Theory Comput. 2012, 8 (9), 3257-3273. https://doi.org/10.1021/ct300400x.

(24) Lim, J. B.; Rogaski, B.; Klauda, J. B. Update of the Cholesterol Force Field Parameters in CHARMM. J. Phys. Chem. B 2012, 116 (1), 203-210. https://doi.org/10.1021/jp207925m.

(25) Vanommeslaeghe, K.; Raman, E. P.; MacKerell, A. D. Automation of the CHARMM General Force Field (CGenFF) II: Assignment of Bonded Parameters and Partial Atomic Charges. J. Chem. Inf. Model. 2012, 52 (12), 3155-3168.

https://doi.org/10.1021/ci3003649.

(26) Vanommeslaeghe, K.; MacKerell, A. D. Automation of the CHARMM General Force Field (CGenFF) I: Bond Perception and Atom Typing. J. Chem. Inf. Model. 2012, 52 (12), 3144-3154. https://doi.org/10.1021/ci300363c.

(27) Jo, S.; Kim, T.; Iyer, V. G.; Im, W. CHARMM-GUI: A Web-Based Graphical User Interface for CHARMM. J. Comput. Chem. 2008, 29, 358-366.

https://doi.org/10.1002/jcc. 
(28) Manjari, S. R.; Banavali, N. K. Structural Articulation of Biochemical Reactions Using Restrained Geometries and Topology Switching. J. Chem. Inf. Model. 2018, 58 (2), 453463. https://doi.org/10.1021/acs.jcim.7b00699. 